\title{
TABLE ERRATA TO "FORMULAS AND THEOREMS FOR THE SPECIAL FUNCTIONS OF MATHEMATICAL PHYSICS" BY W. MAGNUS, F. OBERHETTINGER \& R. P. SONI (1966)
}

\author{
HOWARD S. COHL
}

A Table Errata is submitted concerning a formula in terms of a sum of two Gauss hypergeometric functions for the Ferrers function of the second kind (associated Legendre function of the second kind "on the cut"). This error occurs on p. 167 of Magnus, Oberhettinger \& Soni (1966) Formulas and Theorems for the Special Functions of Mathematical Physics (third enlarged edition, Springer-Verlag, New York).

On p. 167, line 10 from the bottom, for $\left\{\cot \left[\frac{\pi}{2}(\nu+\mu)\right]\right.$, read $\left\{-\cot \left[\frac{\pi}{2}(\nu+\mu)\right]\right.$. With this change in sign, plus the introduction of the factor of $x$ in that same term (the Table Errata for the introduction of the factor of $x$ in this formula, is given in van Haeringen \& Kok (1983) [1]), this formula is consistent with the formula (14.3.12) presented in Olver et al. (2010) [2].

\section{REFERENCES}

[1] H. van Haeringen and L. P. Kok, Table errata: Formulas and theorems for the special functions of mathematical physics, [Springer, New York, 1966; MR38:1291] by W. Magnus, F. Oberhettinger and R. P. Soni, Mathematics of Computation, 41 (164), 775-778, 1983. MR0717720 (84i:33001)

[2] F. W. J. Olver, D. W. Lozier, R. F. Boisvert, and C. W. Clark, editors, NIST handbook of mathematical functions, Cambridge University Press, Cambridge, 2010.

Applied and Computational Mathematics Division, Information Technology Laboratory, National Institute of Standards and Technology, Gaithersburg, Maryland -AndDepartment of Mathematics, University of Auckland, 38 Princes Street, Auckland, NEW ZEALAND

E-mail address: howard.cohl@nist.gov

Received by the editor August 17, 2011.

2010 Mathematics Subject Classification. Primary 33C05.

Key words and phrases. Ferrers functions; associated Legendre functions; hypergeometric functions.

(c) 2012 American Mathematical Society Reverts to public domain 28 years from publication 